\title{
Health status and lifestyle factors as predictors of depression in middle-aged and elderly Japanese adults: a seven-year follow-up of the Komo-Ise cohort study
}

\author{
Hisashi Tanaka', Yosiaki Sasazawa², Shosuke Suzuki ${ }^{3}$, Minato Nakazawa', Hiroshi Koyama ${ }^{1 *}$
}

\begin{abstract}
Background: Depression is a common mental disorder. Several studies suggest that lifestyle and health status are associated with depression. However, only a few large-scale longitudinal studies have been conducted on this topic.

Methods: The subjects were middle-aged and elderly Japanese adults between the ages of 40 and 69 years. A total of 9,650 respondents completed questionnaires for the baseline survey and participated in the second wave of the survey, which was conducted 7 years later. We excluded those who complained of depressive symptoms in the baseline survey and analyzed data for the remaining 9,201 individuals. In the second-wave survey, the DSM-12D was used to determine depression. We examined the risks associated with health status and lifestyle factors in the baseline survey using a logistic regression model.
\end{abstract}

Results: An age-adjusted analysis showed an increased risk of depression in those who had poor perceived health and chronic diseases in both sexes. In men, those who were physically inactive also had an increased risk of depression. In women, the analysis also showed an increased risk of depression those with a BMI of 25 or more, in those sleeping 9 hours a day or more and who were current smokers. A multivariate analysis showed that increased risks of depression still existed in men who had chronic diseases and who were physically inactive, and in women who had poor perceived health and who had a BMI of 25 or more.

Conclusions: These results suggest that lifestyle and health status are risk factors for depression. Having a chronic disease and physical inactivity were distinctive risk factors for depression in men. On the other hand, poor perceived health and a BMI of 25 or more were distinctive risk factors for depression in women. Preventive measures for depression must therefore take gender into account.

\section{Background}

Depression is a common mental disorder that causes psychological anguish and has a substantial impact on one's private and public life [1]. Mental health has been incorporated into the international health policy agenda as a top priority and depression is included in the three leading causes of burden of disease in 2030 estimated by World Health Organization (WHO) [2]. To help prevent

\footnotetext{
* Correspondence: hkoyama@health.gunma-u.ac.jp

'Department of Public Health, Gunma University Graduate School of Medicine, Maebashi, Japan

Full list of author information is available at the end of the article
}

depression, a variety of studies on the risk factors for depression have been conducted worldwide $[3,4]$. Several studies have found that a wide variety of factors, such as socio-demographics, health status, lifestyle and social networks, are involved in the incidence of depression. Studies of non-clinical depression have investigated a variety of risk factors for depression using the Center for Epidemiologic Studies Depression Scale (CES-D) [5]. They have reported that, in females, not having a spouse, living alone, having a disability, having insufficient social support, developing a new health condition, perceiving one's health as poor and having a limited ability to perform physical 
activities significantly increase the risk of depression [6-8]. Other studies using a diagnostic evaluation based on the diagnostic criteria of the Diagnostic and Statistical Manual of Mental Disorders, $4^{\text {th }}$ Edition (DSM-IV) have reported that insomnia, hypersomnia, other sleep complaints, female gender, social isolation, poor self-perceived health and impairment of functional abilities increase the risk of depression $[9,10]$.

As in other industrialized countries, depression has become the most common mental disorder in Japan. Numerous Japanese studies have examined depression in the elderly because Japan is a leader in longevity and possesses an aging society [11]. It has been suggested that lifestyle and health status associate with depression. However, for middle-aged adults, the group with the highest suicide rate in Japan [12], there are a limited number of cross-sectional studies on the risk factors related to depression [13,14]. Miyaji et al. [13] using the CES-D for community residents reported that individuals with good self-perceived health who got more than six hours of sleep per night tended to have a low risk of depression. A study of workers [14] using Zung's Self-Rating Depression Scale [15] reported significantly lower depression scores in males who ate breakfast regularly, engaged in regular physical activity and consumed moderate quantities of alcohol, as well as in non-smoking females who slept 7 to 8 hours per night regularly and engaged in regular physical activity.

To prevent depression, it is necessary to clarify the nature of association between the risk factors and future development of depression. Considering the results of previous studies, we chose three health status items of perceived health status, chronic diseases and body mass index (BMI) and four lifestyle factors including hours of sleep per night, smoking, alcohol consumption and physical activity. In the present study we investigated these factors in non-depressive subjects and analyzed the association with future development of depression in a large-scale longitudinal setting. To understand the underlying factors of developing depression is possibly the first step to prevent depression.

\section{Methods}

\section{Study cohort}

The Komo-Ise study [16,17] included 12,630 middleaged and elderly persons. The original goal of the study was to examine the relationship between lifestyle and sociodemographic risk factors and mortality. Figure 1 shows the number of individuals in the Komo-Ise cohort from 1993-2000. Subjects in the Komo-Ise study were men and women aged 40-69 years living in the village of Komochi and the downtown area of the city of Isesaki who were identified based on the municipal resident registration file in 1993.
Baseline survey: In Komochi, a residents' association in the village distributed self-report questionnaires to households where the potential respondents resided in January 1993. In Isesaki, the same questionnaires were distributed in October 1993 via a health promotion committee. The questionnaire was left at the household to be completed, sealed and collected. There were 4,501 respondents in Komochi (response rate: 92.3\%) and 7,064 in the downtown area of Isesaki (response rate: $91.1 \%)$. Therefore, responses were obtained from a total of 11,565 individuals: 5,630 men (response rate: 91\%) and 5,935 women (response rate: 91\%).

Registration follow-up: The subjects were followed from January 1993 to October 2000. Information on deaths and changes of residence was obtained from data in the municipal resident registration files in each locality. During the follow-up period, 541 deaths (4.7\%) were confirmed to have occurred. Subjects who failed to respond by mail or who were not eligible to respond were defined as lost to follow-up ( $\mathrm{n}=126,1.1 \%$ ).

Second-wave survey: The municipal staffs of Komochi and Isesaki distributed the second wave of the questionnaire in November 2000. The questionnaire was mailed to individuals who had moved away. Responses were obtained from 9,650 of the 10,898 subjects (88.5\%).

The Komo-Ise study was approved by the Epidemiologic Research Ethics Committee of Gunma University Faculty of Medicine, Maebashi, Japan.

\section{Methods}

Questionnaires: The baseline questionnaire elicited information on respondents' demographic characteristics, health status, lifestyle factors and social networks, and also included the Todai Health Index (THI) [18], which quantitatively represents mental and physical complaints. The Japanese-language version of a 1999 survey questionnaire used as part of the Alameda County Study [19] was used for the second-wave survey in 2000. Questions in English were translated by bilingual native speakers according to the process of translation and back-translation. The questionnaire consisted of items on socio-demographics, health (chronic diseases, daily activities, etc.), lifestyle, social networks, mental health, abuse and socioeconomic status.

\section{Depression}

The 12-item scale for depression from the Diagnostic and Statistical Manual of Mental Disorders (DSM-12D) [20] was used to detect depression in the second-wave survey. This is a self-administered questionnaire that mirrors the diagnostic criteria for a major depressive episode in the DSM-IV. The probe statement inquires as to whether the respondent has experienced a particular symptom of depression nearly every day for the past 
Total Designated Sample

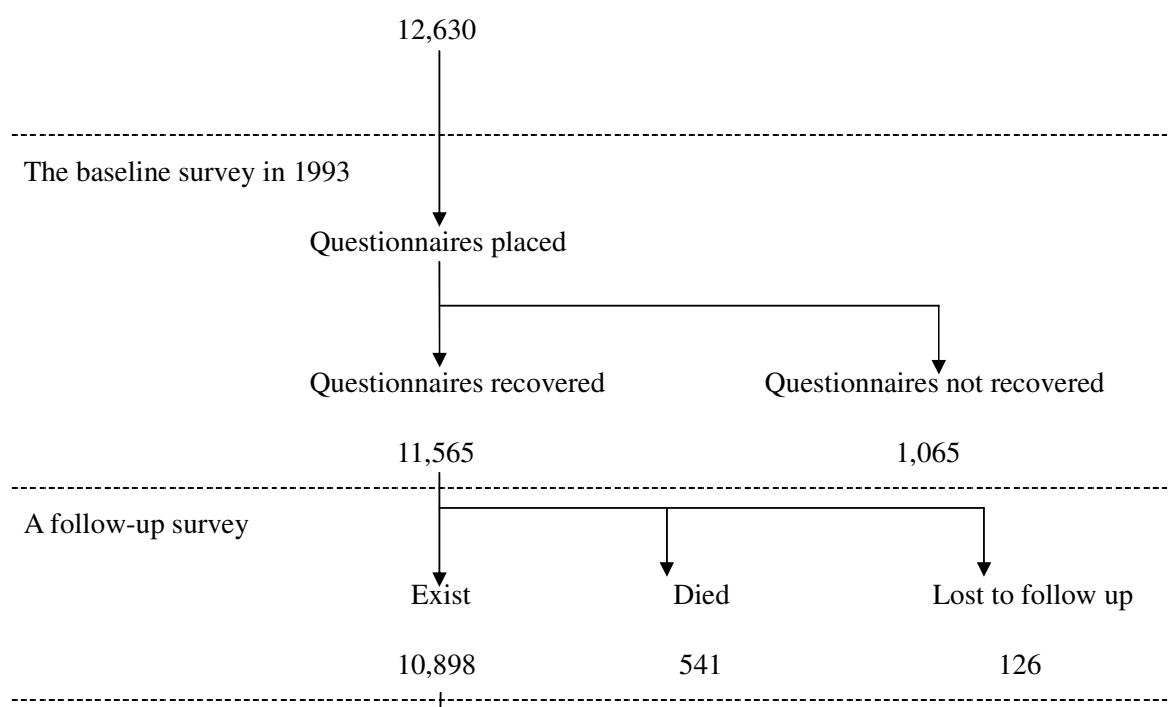

The second wave survey in 2000

Questionnaires placed

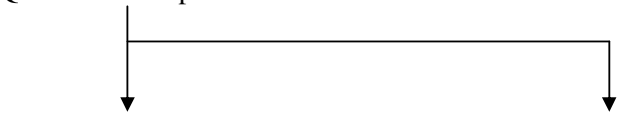

Questionnaires recovered

Questionnaires not recovered

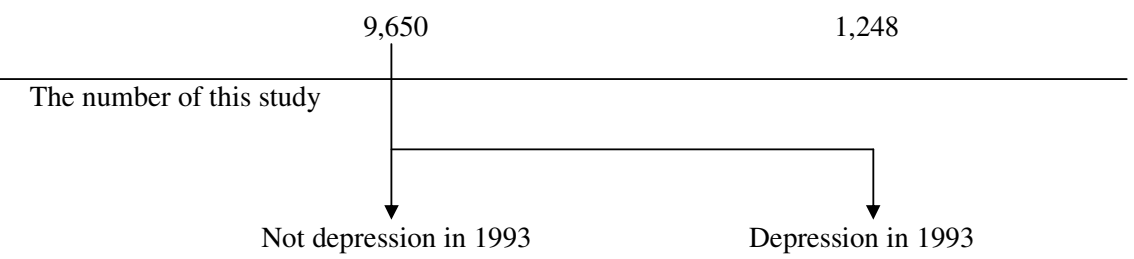

9,201 (Total of analyzed subjects)

449 (excluded)

Figure 1 Number of samples of Komo-Ise cohort 1993-2000.

two weeks. Subjects reporting five or more symptoms of depression, including depressed mood or anhedonia during their usual activities, are diagnosed with a major depressive episode. This method for detecting depression was also used in the Alameda County Study [19,21-23].

\section{Covariates}

Based on the items in the 1993 baseline survey, following three health status items and four lifestyle items were used as covariates.

\section{Health status items}

Three items addressed health: perceived health status, chronic diseases and BMI $(<18.5,18.5-25,>25)$. Perceived health status was assessed by asking, "What is your current health condition: excellent, good, fair, poor, or very poor?" The answers were coded as excellent/good/fair versus poor/very poor.

\section{Lifestyle items}

Four items addressed lifestyle factors: hours of sleep per night ( $<6$ hours, 6-9 hours, $>9$ hours) [24], smoking, alcohol consumption and physical activity. Alcohol consumption was assessed by asking, "Do you drink a lot of alcoholic beverages?" with possible answers of "yes," "only a little," or "never drink."

\section{Adjusted items}

The adjusted socio-demographic items were as follows: age (grouped in five-year intervals), area (Komochi/ downtown Isesaki), education (junior college, college, higher/other), occupation (unemployed, salaried employee, self-employed, agriculture and forestry), and 
social network items. The social network was evaluated through information on the following: 1) marital status, 2) household size, 3) enjoyment of good fellowship with neighbours, 4) participation in activities, and 5) having close friends. The respective questions were as follows: 1 ) What is your current marital status? (Married/single, with divorced and widowed coded as single); 2) How many people do you live with? (Number; dichotomized for analysis into "living alone" versus "two or more persons in the household"); 3) Do you enjoy good fellowship with your neighbours? (Yes/no); 4) How often do you take part in hobbies, club activities, or community groups? (Very often/often/sometimes/never); and 5) When you are in need, do you have close friends you can turn to? (Yes/no).

\section{Subjects of the current analysis}

The 9,650 respondents to the second-wave survey in 2000 were established as the investigation subjects. We excluded 449 respondents: those with a THI score for depression (THI-D) of 22 points or higher in a possible range of 10-30, indicating a high level of depressive symptoms [25] (373 subjects, 176 men and 197 women), and those who reported having a mental illness as a chronic disease (76 subjects, 21 men and 55 women). This left 9,201 subjects in the final sample for analysis (4,326 men, 4,875 women).

\section{Statistical analysis}

Using two logistic regression models adjusted for age alone (model 1) and for age, area, education, occupation, social network (marriage, household, neighborhood, participation, and friends) (model 2), risk factors for major depression in 2000 were evaluated in terms of the odds ratio (OR) and its 95\% confidence interval (CI). SPSS (Version 11.5J) was used for statistical analysis.

\section{Results}

Table 1 shows the characteristics and the social network variables for the subjects included in the analysis and the number cases of depression in 2000 by sex. For men, the prevalence of depression was significantly different between those who were married (1.6\%) and those who were unmarried (3.1\%) and between those living with other people (1.7\%) and those living alone (4.4\%). For women, the prevalence of depression was significantly different between those who reported having friends $(1.5 \%)$ and those who reported having no friends $(2.5 \%)$.

Table 2 shows the health status variables for the subjects in the analysis and the number of cases of depression in 2000. For men, the prevalence of depression was significantly different between those responding "excellent", "good" or "fair" (1.5\%) and those responding "poor" or "very poor" (4.6\%) to the perceived health status variable and between those without (1.1\%) and those with $(2.6 \%)$ chronic disease. For women, the prevalence of depression differed significantly according to all of the variables. The prevalence of depression was 1.7 for those with excellent, good or fair perceived health status versus 5.3 for those with poor and very poor perceived health status. In addition, the prevalence of depression was 1.3 for those with no chronic disease and 3.0 for those with chronic disease. Furthermore, the prevalence of depression was 1.6 for those with a BMI in the 18.5-25 range, 2.1 for those with a $\mathrm{BMI}<18.5$ and 2.9 for those with a BMI of $>25$.

Table 3 shows the lifestyle variables for the subjects in the analysis and the number of associated cases of depression in 2000. For men, the prevalence of depression was significantly different between those who reported no $(2.5 \%)$, light $(1.2 \%)$ and heavy $(2.1 \%)$ alcohol consumption and between those who often and sometimes (1.0\%) and those who never (2.3\%) engaged in physical activity. For women, the prevalence of depression was significantly different between those who slept $6-9$ hours $(1.8 \%),<6$ hours $(3.0 \%)$ and 9 hours $<(6.4 \%)$. The other lifestyle variables did not associate significantly with the prevalence of depression.

Table 4 shows related risk factors by sex according to both models. For men, Model 1 indicated that poor perceived health and suffering from chronic diseases were significant risk factors for the development of depression. The ORs and 95\% CIs for the poor perceived health and chronic disease variables were 2.66, 1.544.57 , and 3.09, 1.54-6.18, respectively. Moreover, model 2 indicated that having chronic diseases was a significant risk factor, OR: 2.19 and 95\% CI: 1.16-4.14. Both model 1 (OR: 2.39 and 95\% CI: 1.36-4.21) and model 2 (OR: 2.58 and $95 \%$ CI: 1.31-5.05) indicated that a lack of physical activity was a significant risk factor for development of depression after 7 years; no such risk factors were found to be associated with the other lifestyle variables.

For women, Model 1 indicated that poor perceived health and suffering from chronic diseases were significant risk factors for the development of depression. The ORs and 95\% CIs for the poor perceived health and the chronic diseases variables were 3.32, 1.80-6.14, and 2.38, 1.48-3.82, respectively. Moreover, Model 2 indicated that having poor perceived health was a significant risk, OR: 2.19 and 95\% CI: 1.16-4.14. Both model 1 (OR: 1.89 and 95\% CI: 1.17-3.08) and model 2 (OR: 1.90 and 95\% CI: 1.08-3.33) indicated that a BMI of $>25$ was a significant risk factor for development of depression. Model 1 also indicated a significant increased risk in 


\begin{tabular}{|c|c|c|c|c|c|c|c|c|}
\hline & & & Men & & & & Women & \\
\hline & $\mathbf{N}$ & $\%$ & Depression(\%) & $p$-value & $\mathrm{N}$ & $\%$ & Depression(\%) & $p$-value \\
\hline Total & & & $63(1.7)$ & & & & $79(1.9)$ & \\
\hline Age class & & & & $p=0.76$ & & & & $p=0.17$ \\
\hline 40-44 years & 783 & 18.1 & $15(2.1)$ & & 752 & 15.4 & $14(2.0)$ & \\
\hline $45-49$ years & 707 & 16.3 & $9(1.4)$ & & 791 & 16.2 & $12(1.7)$ & \\
\hline $50-54$ years & 752 & 17.4 & $14(2.1)$ & & 796 & 16.3 & $12(1.7)$ & \\
\hline $55-59$ years & 693 & 16.0 & $11(1.8)$ & & 929 & 19.1 & $14(1.8)$ & \\
\hline $60-64$ years & 838 & 19.4 & $9(1.4)$ & & 926 & 19.0 & $9(1.3)$ & \\
\hline $65-69$ years & 553 & 12.8 & $5(1.2)$ & & 681 & 14.0 & $16(3.4)$ & \\
\hline Area & & & & $p=0.32$ & & & & $p=0.35$ \\
\hline Rural & 1,872 & 43.3 & $22(1.5)$ & & 1,923 & 39.4 & $33(2.1)$ & \\
\hline Urban & 2,454 & 56.7 & $41(1.9)$ & & 2,952 & 60.6 & $44(1.7)$ & \\
\hline Education & & & & $p=0.37$ & & & & $p=0.26$ \\
\hline Less than high school ar & & & & & & & & \\
\hline & 3,532 & 84.6 & $49(1.7)$ & & 4,347 & 93.4 & $66(1.8)$ & \\
\hline Junior college and colle & & & & & & & & \\
\hline & 643 & 15.4 & $13(2.2)$ & & 307 & 6.6 & $8(2.7)$ & \\
\hline Occupation & & & & $p=0.13$ & & & & $p=0.52$ \\
\hline Any kind of occupation & 4,048 & 96.7 & $56(1.6)$ & & 3,210 & 72.3 & $49(1.8)$ & \\
\hline No occupation & 138 & 3.3 & $4(3.5)$ & & 1,229 & 27.7 & $22(2.1)$ & \\
\hline Marriage & & & & $p<0.05$ & & & & $p=0.62$ \\
\hline Married & 3,661 & 89.3 & $51(1.6)$ & & 3,780 & 82.2 & $56(1.7)$ & \\
\hline Unmarried & 440 & 10.7 & $11(3.1)$ & & 820 & 17.8 & $16(2.4)$ & \\
\hline Household & & & & $p<0.05$ & & & & $p=0.85$ \\
\hline More than 2 & 4,176 & 97.4 & $59(1.7)$ & & 4,592 & 95.2 & $73(1.9)$ & \\
\hline Living alone & 111 & 2.6 & $4(4.4)$ & & 231 & 4.8 & $3(1.7)$ & \\
\hline Neighborhood & & & & $p=0.65$ & & & & $p=0.39$ \\
\hline Yes & 1,590 & 37.7 & $24(1.8)$ & & 2,328 & 49.0 & $40(2.1)$ & \\
\hline No & 2,626 & 62.3 & $37(1.6)$ & & 2,424 & 51.0 & $36(1.7)$ & \\
\hline Participation & & & & $p=0.42$ & & & & $p=0.39$ \\
\hline Yes & 3,165 & 75.3 & $44(1.6)$ & & 3,501 & 73.8 & $52(1.7)$ & \\
\hline No & 1,036 & 24.7 & $18(2.0)$ & & 1,246 & 26.2 & $23(2.2)$ & \\
\hline Friends & & & & $p=0.45$ & & & & $p<0.05$ \\
\hline Yes & 2,526 & 60.3 & $33(1.5)$ & & 3,346 & 70.9 & $44(1.5)$ & \\
\hline No & 1,661 & 39.7 & $27(1.9)$ & & 1,375 & 29.1 & $29(2.5)$ & \\
\hline
\end{tabular}

*Subjects with missing values were excluded from each calculation of proportion. Depression (\%): Number of depression in 2000 (\%). 
Table 2 The number of analysis subject's health status items, and the number of depression in 2000

\begin{tabular}{|c|c|c|c|c|c|c|c|c|}
\hline & \multicolumn{4}{|c|}{ Men } & \multicolumn{4}{|c|}{ Women } \\
\hline & $\mathrm{N}$ & $\%$ & Depression(\%) & $p$-value & $\mathrm{N}$ & $\%$ & Depression(\%) & $p$-value \\
\hline \multicolumn{9}{|l|}{ Health status } \\
\hline Perceived health status & & & & $p<0.001$ & & & & $p<0.001$ \\
\hline Excellent, good, fair & 4,036 & 93.9 & $53(1.5)$ & & 4,568 & 94.2 & $64(1.7)$ & \\
\hline Poor, very poor & 264 & 6.1 & $10(4.6)$ & & 279 & 5.8 & $13(5.3)$ & \\
\hline Chronic disease & & & & $p<0.01$ & & & & $p<0.001$ \\
\hline No & 2,843 & 67.4 & $27(1.1)$ & & 3,119 & 65.9 & $35(1.3)$ & \\
\hline Yes & 1,373 & 32.6 & $30(2.6)$ & & 1,617 & 34.1 & $41(3.0)$ & \\
\hline Body mass index & & & & $p=0.79$ & & & & $p<0.05$ \\
\hline $18.5-25$ & 3,192 & 74.6 & $46(1.7)$ & & 3,474 & 72.3 & $46(1.6)$ & \\
\hline$<18.5$ & 147 & 3.4 & $3(2.5)$ & & 228 & 4.7 & $4(2.1)$ & \\
\hline $25 \leqq$ & 942 & 22.0 & $13(1.6)$ & & 1,103 & 23.0 & $27(2.9)$ & \\
\hline
\end{tabular}

*Subjects with missing values were excluded from each calculation of proportion. Depression (\%): Number of depression in 2000 (\%).

women who slept more than 9 hours per night (OR: 3.78 and 95\% CI: 1.13-12.70) and in women who were current smokers (OR: 2.04 and 95\% CI: 1.08-3.85). In Model 2, no lifestyle variables were associated with a significantly increased risk for the development of depression although the odds ratio of smoking was almost same value as in Model 1.

\section{Discussion}

\section{Health status}

In this study, we showed that health status was a significant risk factor for the development of depression in both men and women. Having chronic diseases was a significant risk factor for depression in men, whereas poor perceived health was a significant risk factor in

Table 3 The number of analysis subject's lifestyle items, and the number of depression in 2000

\begin{tabular}{|c|c|c|c|c|c|c|c|c|}
\hline \multirow{3}{*}{ Lifestyle } & \multicolumn{4}{|c|}{ Men } & \multicolumn{4}{|c|}{ Women } \\
\hline & $\mathbf{N}$ & $\%$ & Depression(\%) & $p$-value & $\mathrm{N}$ & $\%$ & Depression(\%) & $p$-value \\
\hline & & & & & & & & \\
\hline Hours of sleep & & & & $p=0.43$ & & & & $p<0.05$ \\
\hline 6-9 hours & 3,965 & 93.9 & $56(1.7)$ & & 4,431 & 93.0 & $66(1.8)$ & \\
\hline$<6$ hours & 119 & 2.8 & $3(2.9)$ & & 276 & 5.8 & $7(3.0)$ & \\
\hline 9 hours $<$ & 140 & 3.3 & $3(2.9)$ & & 59 & 1.2 & $3(6.4)$ & \\
\hline Smoking & & & & $p=0.90$ & & & & $p=0.07$ \\
\hline Never & 1,133 & 29.3 & $17(1.8)$ & & 4,121 & 88.9 & $58(1.6)$ & \\
\hline Past & 732 & 18.9 & 10(1.6) & & 85 & 1.8 & 2(2.9) & \\
\hline Current & 2,004 & 51.8 & $32(1.9)$ & & 427 & 9.2 & $12(3.3)$ & \\
\hline Alcohol consumption & & & & $p<0.05$ & & & & $p=0.62$ \\
\hline Never & 872 & 20.6 & $18(2.5)$ & & 2,739 & 57.5 & $48(2.1)$ & \\
\hline Light & 2,260 & 53.5 & $23(1.2)$ & & 1,915 & 40.2 & $27(1.6)$ & \\
\hline Heavy & 1,095 & 25.9 & $20(2.1)$ & & 110 & 2.3 & $2(2.0)$ & \\
\hline Physical activity & & & & $p<0.01$ & & & & $p=0.07$ \\
\hline Often, sometimes & 1,995 & 47.3 & $17(1.0)$ & & 1,964 & 41.2 & $23(1.4)$ & \\
\hline Never & 2,224 & 52.7 & $44(2.3)$ & & 2,801 & 58.8 & $52(2.2)$ & \\
\hline
\end{tabular}

*Subjects with missing values were excluded from each calculation of proportion. Depression (\%): Number of depression in 2000 (\%). 
Table 4 Odds ratios of depression in 2000 for variables in 1993

\begin{tabular}{|c|c|c|c|c|c|c|c|c|}
\hline \multirow{3}{*}{ Variable } & \multicolumn{4}{|c|}{ Men } & \multicolumn{4}{|c|}{ Women } \\
\hline & \multicolumn{2}{|c|}{ Model 1} & \multicolumn{2}{|c|}{ Model 2} & \multicolumn{2}{|c|}{ Model 1} & \multicolumn{2}{|c|}{ Model 2} \\
\hline & OR & $(95 \% \mathrm{Cl})$ & OR & $(95 \% \mathrm{Cl})$ & OR & $(95 \% \mathrm{Cl})$ & OR & $(95 \% \mathrm{Cl})$ \\
\hline \multicolumn{9}{|l|}{ Health status } \\
\hline \multicolumn{9}{|l|}{ Perceived health status } \\
\hline Excellent, good, fair & 1.00 & & 1.00 & & 1.00 & & 1.00 & \\
\hline Poor, very poor & $3.09^{b}$ & $(1.54-6.18)$ & 2.02 & $(0.88-4.65)$ & $3.32^{\mathrm{b}}$ & $(1.80-6.14)$ & $2.39^{a}$ & $(1.09-5.24)$ \\
\hline \multicolumn{9}{|l|}{ Chronic disease } \\
\hline No & 1.00 & & 1.00 & & 1.00 & & 1.00 & \\
\hline Yes & $2.66^{b}$ & $(1.54-4.57)$ & $2.19^{\mathrm{a}}$ & $(1.16-4.14)$ & $2.38^{\mathrm{b}}$ & $(1.48-3.82)$ & 1.52 & $(0.86-2.70)$ \\
\hline \multicolumn{9}{|l|}{ Body mass index } \\
\hline $18.5-25$ & 1.00 & & 1.00 & & 1.00 & & 1.00 & \\
\hline$<18.5$ & 1.60 & $(0.49-5.26)$ & 1.40 & $(0.39-4.94)$ & 1.31 & $(0.46-3.68)$ & 1.23 & $(0.37-4.13)$ \\
\hline $25 \leqq$ & 0.92 & $(0.50-1.72)$ & 0.62 & $(0.28-1.36)$ & $1.89^{\mathrm{b}}$ & $(1.17-3.08)$ & $1.90^{\mathrm{a}}$ & $(1.08-3.33)$ \\
\hline \multicolumn{9}{|l|}{ Lifestyle } \\
\hline \multicolumn{9}{|l|}{ Hours of sleep } \\
\hline 6-9 hours & 1.00 & & 1.00 & & 1.00 & & 1.00 & \\
\hline$<6$ hours & 1.72 & $(0.53-5.58)$ & 1.12 & $(0.25-4.95)$ & 1.66 & $(0.75-3.66)$ & 1.48 & $(0.57-3.88)$ \\
\hline 9 hours $<$ & 2.00 & $(0.61-6.63)$ & 2.02 & $(0.43-9.50)$ & $3.78^{\mathrm{a}}$ & $(1.13-12.70)$ & 1.13 & $(0.14-8.98)$ \\
\hline \multicolumn{9}{|l|}{ Smoking } \\
\hline Never & 1.00 & & 1.00 & & 1.00 & & 1.00 & \\
\hline Past & 0.88 & $(0.40-1.94)$ & 0.84 & $(0.34-2.09)$ & 1.67 & $(0.40-6.99)$ & 2.65 & $(0.61-11.59)$ \\
\hline Current & 1.01 & $(0.55-1.83)$ & 1.01 & $(0.50-2.05)$ & $2.04^{\mathrm{a}}$ & $(1.08-3.85)$ & 2.09 & $(0.97-4.51)$ \\
\hline \multicolumn{9}{|l|}{ Alcohol consumption } \\
\hline Never & 1.00 & & 1.00 & & 1.00 & & 1.00 & \\
\hline Light & 0.46 & $(0.25-0.86)$ & 0.54 & $(0.26-1.13)$ & 0.79 & $(0.49-1.28)$ & 0.67 & $(0.37-1.19)$ \\
\hline Heavy & 0.81 & $(0.42-1.55)$ & 0.99 & $(0.46-2.11)$ & 1.01 & $(0.24-4.24)$ & 0.39 & $(0.05-3.08)$ \\
\hline \multicolumn{9}{|l|}{ Physical activity } \\
\hline Often, sometimes & 1.00 & & 1.00 & & 1.00 & & 1.00 & \\
\hline Never & $2.39^{b}$ & $(1.36-4.21)$ & $2.58^{\mathrm{b}}$ & $(1.31-5.05)$ & 1.59 & $(0.96-2.61)$ & 1.23 & $(0.69-2.21)$ \\
\hline
\end{tabular}

Model 1 adjusted for age (5-year age categories). Model 2 adjusted for age (5-year age categories), area (rural/urban), education (compulsory education, high school and vocational or special school/junior college and college or higher), occupation (any kind of occupation/no occupation), social network (marriage; married/unmarried, household; more than 2/living alone, neighborhood; yes/no, participation; yes/no, friends; yes/no).

OR, odds ratio; $95 \% \mathrm{Cl}, 95 \%$ confidence interval. ${ }^{\mathrm{a}}$...P $<0.05$, ${ }^{\mathrm{b}} \ldots \mathrm{p}<0.01$.

women. It has been reported that women with depression have a greater variety of depressive symptoms $[26,27]$, regardless of the presence of chronic diseases.

The results showed gender difference of association of BMI with the development of depression. A previous large-scale study reported that major depressive disorder was associated with a high BMI in women and a low BMI in men [28]. The "jolly fat" hypothesis [29] was substantiated only in men by another study [30], in which the authors speculated that the "jolly fat" hypothesis may not apply to women because they are more likely than men to be stigmatized for being overweight or obese in industrialized societies. Results of meta-analysis of community-based studies [31] and longitudinal studies [32] also show the gender difference. The present study is a longitudinal investigation over 7 years and shows that a BMI of 25 or more in women is a critical factor in the future development of depression. Considering the result of the association between obesity and depression is important to prevent and treat depression of obese women and also prevent and treat obesity in women.

\section{Lifestyle}

The result of Model 1 showed that sleeping longer than 9 hours per night was a risk factor for the development of depression in women. However, Model 2 failed to show such association. The discrepancy of the results implies that the adjusted variables used in model 2 were, al least partly, possible conflicting factors. Previous studies have reported that hypersomnia due to a diagnosed sleep disorder is a risk factor for the development of depression $[9,33,34]$. The number of hours spent sleeping is expected to differ depending on the 
individual and the culture and practices of the population to which he or she belongs, so the current results do not necessarily indicate that sleeping for more than 9 hours per night is a risk factor for the development of depression in women. In addition, a greater number of hours spent sleeping may raise the possibility of low sleep efficiency. However, an improved understanding of what specific sleep duration is a risk factor for the development of depression may make the prevention of depression more effective.

This study found that smoking is a risk factor for the development of depression in women. The result of Model 2 was not significant but showed that smoking is a weak risk factor for the development of depression. The association between smoking and depression has been previously reported [35-39]. In a survey of a Mexican population, Benjet et al. [40] found that the depression scores of male smokers were not significantly higher than those of male non-smokers, but the depression scores of female smokers were higher than those of female non-smokers. They hypothesized that sex-related differences in the social acceptance of smoking, as well as in nicotine metabolism, might influence the risk of depression and suggested that smoking is less socially acceptable for women than for men in Mexico. In Japan, Mino et al. [41] reported that smoking has a greater effect on mental health in women than in men. Similarly, the smoking rate among the current subjects was significantly higher for men (men, $53.2 \%$; women, $10.2 \% ; \mathrm{p}<0.01$ ), suggesting that smoking was not as socially acceptable for women as for men in Japan. Stigmatisation of smoking women could lead to low selfesteem and the development of depression. It is needed to understand such underlying factors related to the association between smoking and development of depression.

In this study, alcohol consumption was not a risk factor for the development of depression in men or women. Several studies have consistently indicated a strong association between alcohol dependence or alcoholism and depression, and alcohol dependence or alcoholism is frequently co-morbid with depression [42-44]. However, these studies were not clear as to whether a drinking habit is a risk factor for the development of depression in the general population. Haynes et al. examined whether excessive alcohol consumption was a risk factor for depression in the general population, but found it not to be associated with the onset of depression [45]. Our results also suggest that drinking habits in non-depressive population are not risk factors for the future development of depression.

Several previous longitudinal studies have shown that moderate physical activity has a beneficial effect on depression, regardless of gender $[19,46,47]$. A clinical study has also demonstrated the anti-depressive effects of physical activity in both men and women [48]. However, in the present study, a lack of physical activity was a risk factor for the development of depression in men but not in women. Using the General Health Questionnaire (GHQ), Ohta et al. [49] also found that the GHQ score decreased with increasing levels of leisure-time exercise and with commuting to work by either walking or cycling in men but not in women. These studies suggest that leisure-time exercise and physical activity while commuting to work are associated with better mental health in men. The result of meta-analysis suggests that even low doses of physical activity may be protective against depression [50].

\section{Limitations}

The first limitation of this study is that we used a selfreport questionnaire to obtain information about the health and lifestyle factors. So we observed perceived recognitions of the subjects to the question items. This implies that affective mode possibly influenced the answers to the items as a confounding factor. The second limitation is a non-response bias due to the likely lack of responses to the second-wave survey from those with severe depressive symptoms. This bias might have led to a possible decrease of depression incidence and an inappropriate estimate of the risk posed by the various factors. The third limitation is that we used DSM$12 \mathrm{D}$ only in the second-wave survey. In the baseline survey, THI-D was used, and those who had depressive symptoms on this measure were excluded. The forth limitation is that the survey was conducted in limited area, and we did not collect information during the follow up period, thus the data were limited in the baseline and second-wave surveys. The last limitation is that there were no items addressing life events and economic problems in this survey. A previous study has shown that life events and economic problems are important factors in the development of depressive symptoms [51].

\section{Conclusions}

We conducted a 7-year longitudinal survey to investigate whether health status and lifestyle factors present risks for the development of depression in community residents between the ages of 40 and 69 years. We found a gender difference in the risk factors predicting the development of depression. Chronic diseases and a lack of physical activity were the risk factors for men; poor perceived health, a BMI of 25 or greater, sleeping more than 9 hours and smoking were the risk factors for women. Preventive measures for depression must therefore take gender into account. 


\section{Acknowledgements}

This research was supported by a Grant-in-Aid (11694243) for Scientific Research from the Ministry of Education, Culture, Sports, Science, and Technology, Japan, and a Gerontology and Health Grant from Gunma Prefecture. The authors wish to express their gratitude to the mayors and staff of the Village of Komochi and the City of Isesaki for their support.

\section{Author details}

'Department of Public Health, Gunma University Graduate School of Medicine, Maebashi, Japan. ${ }^{2}$ Faculty of Education, University of the Ryukyus, Okinawa, Japan. ${ }^{3} \mathrm{NPO}$ International Ecohealth Institute, Isesaki, Japan.

\section{Authors' contributions}

HT was involved in data analysis and interpretation of the results, in addition to writing the manuscript. YS and SS established the concept and design of the Komo-Ise cohort study and carried out the data collection. MN contributed statistical analysis and interpretation of the results. HK supervised the data analysis and contributed to interpretation of the results and editing the manuscript. All authors contributed the interpretation and discussion of the results. They read and approved the final manuscript. The authors have no potential conflicts of interest to be disclosed.

\section{Competing interests}

The authors declare that they have no competing interests.

Received: 8 September 2010 Accepted: 7 February 2011

Published: 7 February 2011

\section{References}

1. American Psychiatric Association: Practice guideline for major depressive disorder in adults. Am J Psychiatry 1993, 150(Suppl 4):1-26.

2. Mathers CD, Loncar D: Projections of global mortality and burden of disease from 2002 to 2030. PLoS Med 2006, 3:e442-e512.

3. American Psychiatric Association: DSM-IV: Diagnostic and Statistical Manual of Mental Disorders. 4 edition. Washington DC: 1994

4. Cole MG, Dendukuri N: Risk factors for depression among elderly community subjects: a systematic review and meta-analysis. Am J Psychiatry 2003, 160:1147-1156.

5. Radloff LS: The CES-D scale: a self report depression scale for research in the general population. Appl Psychol Meas 1977, 1:385-401.

6. Kennedy GJ, Kelman HR, Thomas C, Wisniewski W, Metz H, Bijur PE: Hierarchy of characteristics associated with depressive symptoms in an urban elderly sample. Am J Psychiatry 1989, 146:220-225

7. Kennedy GJ, Kelman HR, Thomas C: The emergence of depressive symptoms in late life: the importance of declining health and increasing disability. J Community Health 1990, 15:93-104.

8. Harlow SD, Goldberg EL, Comstock GW: A longitudinal study of risk factors for depressive symptomatology in elderly widowed and married women. Am J Epidemiol 1991, 134:526-538.

9. Roberts RE, Shema SJ, Kaplan GA, Strawbridge WJ: Sleep complaints and depression in an aging cohort: a prospective perspective. Am J Psychiatry 2000, 157:81-88.

10. Kivela SL, Kongas-Saviard P, Kimmo P, Kesti E, Laippala P: Health, health behaviour and functional ability predicting depression in old age: a longitudinal study. Int J Geriatr Psychiatry 1996, 11:871-877.

11. Masuchi A, Kishi R: A review of epidemiological studies on the relationship of social networks and support to depressive symptoms in the elderly. Nippon Koshu Eisei Zasshi 2001, 48:435-448.

12. Ministry of Health, Labour, and Welfare, Japan: White Paper on the Labour Economy Tokyo; 2004.

13. Miyaji NT, Higashi A, Ozasa K, Watanabe Y, Aoike A, Kawai K: Depression, health status and lifestyles of residents of a rural community. Nippon Koshu Eisei Zasshi 1994, 41:452-460.

14. Kawakami N, Haratani T, Kaneko T, Koizumi A: Relationship between health practices and depressive mood among industrial workers. Sangyo lgaku 1987, 29:55-63.

15. Zung WWK: A self-rating depression scale. Arch Gen Psychiatry 1965, 12:63-70.
16. Ohta A, Aoki S, Takeuchi K, Yosiaki S, Suzuki S: Lifestyle and sociodemographic risk factors for death among middle-aged and elderly residents in Japan from a five-year follow-up cohort study. J Epidemiol 2001, 11:51-60.

17. Iwasaki M, Otani T, Sunaga R, Miyazaki H, Xiao L, Wang N, Yosiaki S, Suzuki S: Social networks and mortality based on the Komo-lse cohort study in Japan. Int J Epidemiol 2002, 31:1208-1218.

18. Suzuki S, Roberts RE: Methods and applications in mental health surveys. Todai Health Index Tokyo: University of Tokyo Press; 1991.

19. Strawbridge WJ, Deleger S, Roberts RE, Kaplan GA: Physical activity reduces the risk of subsequent depression for older adults. Am J Epidemiol 2002, 156:328-334

20. Spitzer RW, Williams JB, Kroenke K, Linzer M, deGruy FV, Hahn SR, Brody D, Johnson JG: Utility of a new procedure for diagnosing mental disorders in primary care: The PRIME-MD 1000 study. JAMA 1994, 272:1749-1756.

21. Roberts RE, Kaplan GA, Shema SJ, Strawbridge WJ: Does growing old increase the risk for depression? Am J Psychiatry 1997, 154:1387-1390.

22. Roberts RE, Kaplan GA, Shema SJ, Strawbridge WJ: Prevalence and correlates of depression in an aging cohort: the Alameda County Study. J Gerontol B Psychol Sci Soc Sci 1997, 52:S252-S258.

23. Roberts RE, Strawbridge WJ, Kaplan GA: Are the fat more jolly? Ann Behav Med 2002, 24:169-180.

24. Hartmann E, Baekeland F, Zwilling G, Hoy P: Sleep need: how much sleep and what kind? Am J Psychiatry 1971, 127:1001-1008.

25. Kawada T, Suzuki S, Kubota F, Ohnishi N, Satoh K: Content and cross validity of the Todai Health Index depression scale in relation to the Center for Epidemiologic Studies Depression Scale and the Zung Selfrating Depression Scale. J Occup Health 1994, 41:154-159.

26. Weissman MM, Klerman GL: Sex difference and the epidemiology of depression. Arch Gen Psychiatry 1977, 34:98-111.

27. Kroenke K, Spitzer RL: Gender differences in the reporting of physical and somatoform symptoms. Psychosoma Med 1998, 60:150-155.

28. Carpenter KM, Hasin DS, Allison DB, Faith MS: Relationships between obesity and DSM-IV major depressive disorders, suicide ideation, and suicide attempts: results from a general population study. Am J Public Health 2000, 90:251-257.

29. Crisp AH, McGuiness B: Jolly fat: relation between obesity and psychoneurosis in general population. Br Med J 1976, 1:7-9.

30. Palinkas LA, Wingard DL, Barrett-Connor E: Depressive symptoms in overweight and obese older adults: a test of the "jolly fat" hypothesis. J Psychosom Res 1996, 40:59-66.

31. De Wit L, Luppino F, van Straten A, Penninx B, Zitman F, Cuijpers P: Depression and obesity: a meta-analysis of community-based studies. Psychiatry Res 2010, 178:230-235.

32. Luppino FS, de Wit LM, Bouvy PF, Stijnen T, Cuijpers P, Penninx BW, Zitman FG: Overweight, obesity, and depression: a systematic review and meta-analysis of longitudinal studies. Arch Gen Psychiatry 2010, 67:220-229.

33. Ford DE, Kamerow DB: Epidemiologic study of sleep disturbances and psychiatric disorders. An opportunity for prevention? JAMA 1989 262:1479-1484.

34. Breslau N, Roth T, Rosenthal L, Andreski P: Sleep disturbance and psychiatric disorders: a longitudinal epidemiological study of young adults. Biol Psychiatry 1996, 39:411-418.

35. Anda R, Williamson D, Escobedo L, Mast E, Giovino G, Remington P: Depression and the dynamics of smoking: a national perspective. JAMA 1990, 264:1541-1545.

36. Glassman AH, Helzer JE, Covey LS, Cottler LB, Stetner F, Tipp JE, Johnson J: Smoking, smoking cessation, and major depression. JAMA 1990, 264:1546-1549.

37. Kendler K, Neale M, Maclean C, Heath A, Eaves L, Lessler R: Smoking and major depression: a causal analysis. Arch Gen Psychiatry 1993, 50:36-43.

38. Covey L, Glassman AH, Stetner F: Cigarette smoking and major depression. J Addict Dis 1998, 17:35-46.

39. Breslau N, Peterson EL, Schultz LR, Chilcoat HD, Andreski P: Major depression and stages of smoking. Arch Gen Psychiatry 1998, 55:161-166.

40. Benjet C, Wagner FA, Borges GG, Medina-Mora ME: The relationship of tobacco smoking with depressive symptomatology in the Third Mexican National Addictions. Psychol Med 2004, 34:881-888.

41. Mino Y, Shigemi J, Otsu T, Ohta A, Tsuda T, Yasuda N, Babazono A, Yamamoto E: Smoking and mental health: cross-sectional and cohort studies in an occupational setting in Japan. Prev Med 2001, 32:371-375. 
42. Regier D, Farmer M, Rae D, Locke B, Keith S, Judd L, Goodwin F: Comorbidity of mental disorders with alcohol and other drug abuse: results from the Epidemiologic Catchment Area (ECA) study. JAMA 1990, 264:2511-2518

43. Kessler RC, McGonagle KA, Zhao S, Nelson C, Hughes M, Kendler K: Lifetime and 12-mouth prevalence of DSM-III-R psychiatric disorders in the United States: results from the National Comorbidity Survey. Arch Gen Psychiatry 1994, 51:8-19.

44. Swendsen JD, Merikangas KR: The comorbidity of depression and substance use disorders. Clin Psychol Rev 2000, 20:173-189.

45. Haynes JC, Farrell M, Singleton N, Meltzer H, Araya R, Lewis G, Wiles NJ: Alcohol consumption as a risk factor for anxiety and depression: results from the longitudinal follow-up of the National Psychiatric Morbidity Survey. Br J Psychiatry 2005, 187:544-551.

46. Camacho TC, Roberts RE, Lazarus NB, Kaplan GA, Cohen RD: Physical activity and depression: evidence from the Alameda County Study. Am J Epidemiol 1991, 134:220-231

47. Lampinen $\mathrm{P}$, Heikkinen $\mathrm{RL}$, Ruoppila I: Changes in intensity of physical exercise as predictors of depressive symptoms among older adults: an eight-year follow-up. Prev Med 2000, 30:371-380.

48. Blumenthal JA, Babyak MA, Doraiswamy PM, Watkins L, Hoffman BM, Barbour KA, Herman S, Craighead WE, Brosse AL, Waugh R, Hinderliter A, Sherwood A: Exercise and pharmacotherapy in the treatment of major depressive disorder. Psychosom Med 2007, 69:587-596.

49. Ohta M, Mizoue T, Mishima N, Ikeda M: Effect of the physical activities in leisure time and commuting to work on mental health. $J$ Occup Health 2007, 49:46-52.

50. Teychenne M, Ball K, Salmon J: Physical activity and likelihood of depression in adults: a review. Prev Med 2008, 46:397-411.

51. Wong SY, Chan D, Leung PC: Depressive symptoms in middle-aged men: Results from a household survey in Hong Kong. J Affect Disord 2006, 92:215-220.

\section{Pre-publication history}

The pre-publication history for this paper can be accessed here: http://www.biomedcentral.com/1471-244X/11/20/prepub

doi:10.1186/1471-244X-11-20

Cite this article as: Tanaka et al:: Health status and lifestyle factors as predictors of depression in middle-aged and elderly Japanese adults: a seven-year follow-up of the Komo-Ise cohort study. BMC Psychiatry 2011 11:20.

\section{Submit your next manuscript to BioMed Central and take full advantage of:}

- Convenient online submission

- Thorough peer review

- No space constraints or color figure charges

- Immediate publication on acceptance

- Inclusion in PubMed, CAS, Scopus and Google Scholar

- Research which is freely available for redistribution 